\title{
What the giant tells us about agreeing post-verbal subjects in Xhosa
}

\section{Eva-Marie Bloom Ström}

Department of Languages and Literatures, University of Gothenburg, Sweden; and Department of English Language and Linguistics, Rhodes University, South Africa

E-mail: eva-marie.strom@sprak.gu.se

\begin{abstract}
Constructions with the subject following the verb are a widely studied topic in Bantu linguistics. One such construction, in which the subject is dislocated, is considered not as core subject inversion, but generally as an afterthought construction. This study takes a spoken text, in this case a narrative, as its point of departure to examine this kind of construction more carefully in terms of its function and morphosyntactic structure in Xhosa, a Bantu language of South Africa. The paper shows that such agreeing post-verbal subject constructions are used to re-activate semi-active concepts that have been mentioned previously in the narrative. They reintroduce a concept which then becomes the topic of the current sentence and of subsequent phrases, in which the subject is often pronominalized. It is also shown that the expected penultimate lengthening, one of the diagnostics used to differentiate core inversion from constructions with a dislocated subject, is often not present. The function of the construction and other morphosyntactic diagnostics point to the subject being dislocated, however. Furthermore, it is argued, based on a few examples from the narrative and follow-up grammaticality judgements, that there is agreeing inversion in Xhosa, with the subject in the immediately-after-verb position. This inversion construction has not previously been attested in Xhosa and further research is needed in order to corroborate the results. The appendix presents the recorded, transcribed, glossed and translated narrative on which the analysis is based.
\end{abstract}

Keywords: Xhosa, subject inversion, information structure, phonological phrasing, thetic sentences

\section{Introduction}

This paper analyses constructions in Xhosa where the subject follows the verb and there is agreement on the verb with this post-verbal subject ${ }^{1}$. Constructions with a post-verbal agreeing subject are not uncommon in Xhosa and other Bantu languages; for an overview, see Marten and van der Wal (2014). There are in fact two kinds of such constructions, superficially similar but different in their syntax and information structure. The first has been analysed as having a

\footnotetext{
${ }^{1}$ I thank Jenneke van der Wal, two anonymous reviewers, and the audiences of the SAMWOP 2015 workshop in Grahamstown and the Bantu6 conference in Helsinki for comments on the paper and the data discussed herein.
} 
subject that is right-dislocated out of the verb phrase, as in an afterthought construction, comparable to English "In the morning they crowed, the roosters". They are traditionally described as being used for predicate focus, with the post-verbal subject as the dislocated topic or anti-topic (Chafe 1976; Lambrecht 1994). For ease of reference, I will call these structures "agreeing post-verbal subject constructions" in this paper. An example is the following, from Otjiherero (Marten 2011:801):

$$
\begin{aligned}
& V \text {-è-yá, òvà-éndà. } \\
& \text { SM2-PAST-come 2-visitors } \\
& \text { 'They came, the visitors.' }
\end{aligned}
$$

[Otjiherero]

Secondly, many Bantu languages have inversion constructions with the (logical) subject inside the verb phrase in a close bond with the verb. These are "core inversion constructions". When the verb agrees with the post-verbal subject, they are referred to as "agreeing inversion" and are used for subjects that lack topicality; i.e. subject focus and thetic ${ }^{2}$ constructions (Marten and van der Wal 2014). For Xhosa, data are lacking with regard to the agreeing inversion construction, and it is reported not to be allowed in Zulu (Marten and van der Wal 2014). The following phrase is an example from the Matengo language. It can be the answer to "What has fallen down?", i.e. subject focus, or it can be used as a thetic sentence whereby all parts of the sentence are new information (Nobuko 2011:756):

$$
\begin{aligned}
& \text { Gu-hábwiki ńko:ngo. } \\
& \text { 3SM-fall.PERF 3.tree } \\
& \text { 'A tree has fallen down.' }
\end{aligned}
$$

[Matengo]

The aim of this paper is to analyse inversion constructions in more natural spoken language in order to critically examine the diagnostics for agreeing inversion vs. agreeing post-verbal subject. The analysis takes as its point of departure a transcribed, glossed and translated narration of a story ${ }^{3}$. Firstly, the data presented in this paper show that there is agreeing inversion in Xhosa. Consider the following example ${ }^{4}$ :

$$
\begin{aligned}
& \text { kwâ:sa za-khál(a) inkukhu } \\
& \text { in.the.morning 10SM.PST-cry 10.rooster } \\
& \text { 'In the morning the roosters crowed.' }
\end{aligned}
$$

\footnotetext{
${ }^{2}$ Thetic sentences lack a topic-comment structure and are used for the presentation of an event as a whole, also referred to as "all-new" or "sentence focus" (Sasse 1996; Lambrecht 2000; van der Wal 2008).

${ }^{3}$ I.e. more natural than elicited examples. A folktale story is of course a specific kind of genre not much used in everyday speech. Nevertheless, it is not a written text, but is freely told from the mind of the narrator.

${ }^{4}$ Parentheses indicate that the vowel is not heard, often written as zakhal' inkhuku in Xhosa texts. For glossing reasons, it is important to know what the missing vowel is. A colon indicates lengthening of the preceding vowel. A complete list of glossing abbreviations is included in the appendix. The final vowel (FV) is not always glossed separately in the examples.

${ }^{5}$ All Xhosa examples are followed by a code consisting of an abbreviation of the place name, plus the date of the recording and a letter indicating how the data have been obtained. In the case of our story, this letter is $\mathrm{O}=\mathrm{oral}$ tradition, story, legend. The story is told by Nomawethu Wole Nkwaqa, a woman in her forties from Port St Johns. All examples from this story are coded [PSJ150517O]. The text has been discussed and follow-up questions asked with Ntombifikile Futu, a woman in her twenties from Nqileni, as well as with Sikelelwa Qwazi, a woman in her twenties from Port Elizabeth. Examples from these consultants, as well as examples from other speakers, are coded with initials, e.g. [NF160404E]. The last letter E indicates that these are elicited examples. Moreover, they have
} 
The subject follows the verb, and agreement on the verb is with the post-verbal subject iinkúkhu 'rooster' (in noun class 10, but here with a short initial vowel). As further explained in section 3.3, phonological phrasing is evidence of a close link between the verb and the post-verbal noun phrase. As the penultimate vowel of the verb -khâla 'crow' is short, this is an indication that such a close link exists and that this phrase is an example of agreeing inversion ${ }^{6}$. Moreover, the phrase in (3) is used in a thetic construction.

Secondly, the paper aims to determine in more precise terms the function and discourse properties of the agreeing post-verbal subject construction. In terms of information structure, it is shown - as expected - that the agreeing post-verbal subject is often used to re-activate concepts that have recently been mentioned and to introduce them as the topic of the current sentence. In terms of the morphosyntactic structure of the agreeing post-verbal subject, however, we will see that the diagnostics generally used in order to distinguish agreeing postverbal subject from agreeing inversion in Bantu languages are not always available. One of the most important clues as to whether a subject is dislocated is phonological phrasing. A subject that is inside the verb phrase is phrased phonologically with the verb. In Otjiherero, the evidence for such phrasing is tonal, and in Matengo there are several clues to the phrasing, including tone and penultimate lengthening. In Xhosa, phonological phrasing is evidenced by penultimate vowel lengthening.

This paper will show that penultimate lengthening is not always a clear indication of dislocation in agreeing post-verbal subject constructions in Xhosa. This makes it very difficult to tell agreeing post-verbal subject and agreeing inversion apart in tenses where there is no distinction between conjoint and disjoint verb forms - another clue to the distinction between agreeing inversion and agreeing post-verbal subject. Most examples in the narrative are in the remote past, as in the following:

$$
\begin{aligned}
& \text { wá-bás }(a) \quad \text { uNomaha:mle } \\
& \text { 1SM.PST-kindle uNomahamle } \\
& \text { 'Nomahamle kindled the fire.' }
\end{aligned}
$$

[PSJ150517O]

The subject follows the verb, and agreement on the verb is with the post-verbal subject uNomahamle (a name, triggering agreement of noun class 1). There appears to be a close link between the verb and the post-verbal noun phrase, as evidenced by the phonological phrasing: the penultimate vowel of the verb basa 'kindle' is not lengthened. The subject is semi-active in terms of its information structure, as is typical for agreeing post-verbal subject (see section 4.1).

This paper will address the following questions: What are the information-structural contexts in which agreeing post-verbal subject is used? What is the phonological phrasing of the construction? How do we differentiate this construction from agreeing inversion when the phonological phrasing is often not the expected one? What about other diagnostics used to determine whether the subject is dislocated out of the verb phrase? The paper also contributes a transcribed, glossed and translated text in which the agreeing post-verbal subject construction is amply used: "The two girls who escaped from a giant".

\footnotetext{
the initials of the speaker rather than the place name. Freely-given phrases based on stimuli (e.g. cartoons) have the letter S. I am deeply grateful to all speakers who have contributed to the study.

${ }^{6}$ The penultimate vowel in the last word is also not long. This is due to the speaker continuing with the sound of the roosters (see the appendix).
} 
The paper is structured as follows: firstly, in section 2, the micro-variation project within which this research was conducted is briefly introduced, together with a discussion of the methodology. Section 3 argues that there is agreeing inversion in Xhosa and gives a background to subject inversion, information structure, and the diagnostics needed to distinguish core inversion constructions from agreeing post-verbal subjects. Section 4 analyses the agreeing post-verbal subject construction, firstly in terms of information structure in 4.1, then examining the diagnostics for subject inversion vs. dislocation in 4.2 (phonological phrasing) and 4.3 (other diagnostics). A summary and conclusions are offered in section 5, and the story is presented in the appendix.

\section{Subject inversion in a micro-variation project}

This paper reports results from the project Morphosyntactic variation in the dialects of Xhosa, based on data collected through research in the Eastern Cape in South Africa. Xhosa is a Bantu language of the Nguni group, closely related to other Nguni varieties and especially to Zulu. As with most languages, Xhosa is a cluster of dialects, bordering on the Zulu cluster of dialects and without a clear-cut boundary between the two. The Xhosa standard is based on a few of the dialects (Doke 1954), and most publications on the Xhosa language take this standard as the object of study. Variation in other parts of the Xhosa-speaking area remains relatively understudied (Nyamende 1994). This project does not focus on determining what the Xhosa dialects are, their interrelatedness, and the boundaries between them; rather, it is concerned with any variation encountered, be it geographical or based on e.g. socio-economic factors, gender, age or register. Geographical borders - those of the Eastern Cape - have however been used in order to narrow down the scope of the project. The Eastern Cape is the nucleus of the Xhosaspeaking area.

Subject inversion is one of the morphosyntactic categories studied for this project. It is a complex phenomenon involving phonology (phrasing), morphology (conjoint/disjoint form of the verb), syntax (order of elements), and information structure. Studies carried out on subject inversion in the Bantu language family have shown how the different constructions appear across the family, but also how closely related languages can differ in this domain, making it an interesting candidate for a micro-variation project (Marten and van der Wal 2014).

The micro-variation project is based entirely on fieldwork carried out across the Eastern Cape. The analysis of different morphosyntactic constructions is based on transcribed recordings of spoken Xhosa, which represent how the language functions in actual daily use. Additional elicitation is based on examples from texts, i.e. follow-up questions have been asked in order to test the borders of grammaticality. Traditional elicitation of translated phrases is avoided in this way. For the specific kind of inversion construction presented in this article - agreeing post-verbal subject - a narration of a story to children (see appendix) has been used as the point of departure. Transcription and analysis of further texts is in progress, and the current study therefore focuses on one text with additional elicitation for clarification. The findings presented here will be checked against more data in future analyses.

\section{Agreeing inversion in Xhosa}

This section will look into examples from the text that can be labelled "agreeing inversion"; a category of inversion constructions that have so far not been attested in Xhosa. In order to 
analyse these constructions, the diagnostics used to establish core inversion constructions are considered in section 3.3. Firstly, however, section 3.1 introduces subject inversion more generally in the language, and section 3.2 discusses the effects of subject inversion with respect to the information structure of a sentence.

\subsection{Inverted subjects}

The default word order of Xhosa and other Bantu languages is $\mathrm{SV}(\mathrm{O})$. There is an obligatory subject agreement marker (SM) on the verb, agreeing with the (optional) preverbal subject in person and noun class:

$$
\begin{aligned}
& \text { uSiph (o) u-rhálel-(a) úmphoko:qo } \\
& \text { Sipho 1SM-like-FV 3.umphokoqo } \\
& \text { 'Sipho likes umphokoqo' (a dish with maize and milk). }
\end{aligned}
$$

[SN150925E]

Bantu languages are relatively free with the manipulation of word order for informationstructural reasons, and the subject frequently occurs in the post-verbal position. This has been extensively studied in Bantu linguistics, both for individual languages and comparatively (e.g. Bresnan and Kanerva 1989; Demuth 1990; Demuth and Mmusi 1997; Marten 2006; Zerbian 2006; Buell 2007; Marten 2011; Creissels 2011; Zeller 2013; Marten and van der Wal 2014). The core inversion constructions are recognised through certain diagnostics, to be presented in section 3.3, and have in common that the post-verbal subject is non-topical. There are different kinds of subject inversion constructions. In the first category, a pre-verbal noun referring to semantic roles such as location, instrument, and patient - for a full overview see Marten and van der Wal (2014) - determines the agreement on the verb, with the logical subject following the verb. The noun referring to location can be marked by locative morphology (noun classes 16-18), referred to as "formal locative inversion", or the noun can lack such locative morphology, in which case it is referred to as "semantic locative inversion", as in the following example from Zulu (Zeller 2013):

$$
\begin{aligned}
& \text { i-n-gadi } \quad \text {-mil-a } \quad \text {-tshani } \\
& \text { AUG-9-garden 9.SM-grow-FV AUG-14.grass } \\
& \text { 'In the garden grows grass.' }
\end{aligned}
$$

The semantic locative inversion construction, as exemplified in (6), is also accepted in Xhosa, according to my consultants.

In the second category of inversion constructions, there is no pre-verbal argument. Either the agreement on the verb is with the post-verbal subject, referred to as "agreeing inversion" and discussed below, or the agreement is with the default subject marker $\mathrm{ku}$-, followed by the conjoint form of the verb (du Plessis and Visser 1992:130; Carstens and Mletshe 2015). This is a commonly used construction in Xhosa and referred to as "default agreement inversion" (Marten and van der Wal 2014) ${ }^{7}$ :

\footnotetext{
${ }^{7}$ The example from the text includes the coordinator $n a$ 'and', which is not required in this type of construction.
} 


\author{
kú-khála nê:-ntá:ka \\ 17SM-sing and-10.birds (na+iintaka) \\ 'and the birds were singing...'
}

[PSJ150517O]

The construction with the non-agreeing subject is used in thetic (all-new or presentational focus) sentences, as in (7), as well as in subject focus (Carstens and Mletshe 2015). The thetic construction can be elicited by asking Kutheni? 'What happened?', and is used in out-of-theblue contexts. The subject focus construction is elicited by asking, for example, Kulime bani? 'Who cultivated?'. What these two have in common - as with other core inversion constructions - is the non-topicality of the subject. Default agreement inversion can be used with both intransitive and transitive verbs in Xhosa (du Plessis and Visser 1992:130-133).

We now turn to agreeing inversion, in which the verb agrees with the post-verbal subject. This was exemplified in (2) for Matengo. As the remainder of section 3 will show, such constructions also exist in Xhosa. In the text, a new situation is introduced a few times in the following way:

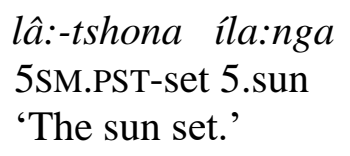

[PSJ150517O]

This is a thetic expression where the whole sentence is in focus (no topic-comment structure). As agreeing inversion constructions have not previously been established for Xhosa, I expected that a default agreement inversion construction, as in (7), would be used. However, the construction in (8) has a formal resemblance with the agreeing post-verbal subject construction, where the subject noun phrase follows the verb in a dislocated position and the subject agreement on the verb is with this post-verbal subject, as shown for Otjiherero in (1) and for Xhosa in (9). The difference between the two can be determined by a set of diagnostics discussed in section 3.3. Firstly, as these constructions are said to differ in information structure, the following section will examine the way in which this difference manifests itself.

$$
\begin{aligned}
& \text { wá-fák(a) ilí:tye umfa:na } \\
& \text { 1SM.PST-put 5.stone 1.man } \\
& \text { 'The man put a stone (inside).' }
\end{aligned}
$$

$[\mathrm{NF} 160405 \mathrm{E}]$

\title{
3.2 Information structure of VS constructions
}

Information structure is concerned with how a language packages an idea in different ways, depending on (i) what the speaker assumes the hearer already has in her mind and can relate to, and (ii) the intentions of the speaker with regard to what is more important in the message and what is backgrounded. The idea or message in itself has the same truth value regardless of the different ways that it can be packaged (see for example Lambrecht (1994) and Krifka (2006)). We have seen that the canonical word order in Xhosa is $\mathrm{SV}(\mathrm{O})$, and that the word order can be changed without changing the truth value of the message. The speaker's choice to use a VS construction is a matter of packaging.

Such packaging can represent the speaker's assumption about the mental representation of the referent, i.e. whether the referent is identifiable by the hearer and how recently a representation of this identifiable referent has been activated (Lambrecht 1994), or, to put it another way, what 
the cognitive status of the referent is in the hearer's mind (Gundel, Hedberg and Zacharski 1993). In Chafe's (1987) terms, a concept can be active at the moment of speaking. Such concepts are often pronominalised or not verbalised at all. An example is when a speaker says "..this was uh... a biology course", where "this" refers to an undergraduate course already activated previously in the discourse (Chafe 1987:27). A concept is semi-active or accessible if it is in background awareness because it has been mentioned before or because it is expected based on its relatedness to other things that have been mentioned; i.e. it is part of a schema of concepts related to a certain mentioned concept (e.g. the concept 'students' is expected in relation to the undergraduate course mentioned above). Semi-active concepts can also be present in the text-external world (Lambrecht 1994). Inactive concepts are newly brought into the conversation, as with "biology course" in the example above from Chafe (1987).

These ideas of identifiability, activation, and cognitive status are called "pragmatic states" (Lambrecht 1994) and are interrelated with the ideas of topic and focus, which concern the pragmatic roles that a referent - which has certain identifiability and activation properties - can play in a proposition (Lambrecht 1994). Topic and focus are relational categories, where the topic of a sentence is the thing that the proposition is about, while focus indicates that the referent is unpredictable in the situation, and draws specific attention to it.

For Bantu languages, as summarised in Marten and van der Wal (2014), the information structure of the sentence determines the use of the different structures available with a postverbal subject, as post-verbal subjects are used to express (non-)topicalisation of subjects. In core inversion constructions, the subject is not the topic in terms of 'what the sentence is about'. Rather, the subject is either in focus, or it is part of a thetic construction that introduces new information. A pre-verbal expression typically functions as the topic. Agreeing inversion is one of these core inversion constructions. The following example is from Makhuwa (Marten and van der Wal 2014):

$$
\begin{aligned}
& \text { ni-hoó-wá n-láikha } \\
& \text { SM5-PRF-DJ-come 5-angel } \\
& \text { 'There came an angel.' }
\end{aligned}
$$

[Makhuwa]

Agreeing inversion thus differs from agreeing post-verbal subject, where the subject comes after the verb but is dislocated, as we shall see in the following section. In such constructions, the subject is discourse-old (or active), and the verbal agreement marker "can be analysed as agreeing with a contextually given discourse topic rather than with the right-dislocated DP directly" (Marten and van der Wal 2014:36). It is this function of the agreeing post-verbal subject that we will examine further in the text.

\subsection{Diagnostics for VS constructions}

Our understanding, then, of the function of a certain VS construction depends on the information structure of the sentence and the discourse. Moreover, there is morphosyntactic and phonological evidence for the existence of the specific inversion construction concerned. Marten and van der Wal (2014) summarise the diagnostics that have been set out in previous studies. Such diagnostics help us to determine whether the construction in question concerns core inversion, where the post-verbal subject is phrased with the verb, or whether the post- 
verbal subject is right-dislocated out of the verb phrase. These diagnostics will be presented here.

Firstly, in a core inversion construction, the inverted subject cannot be left out (Marten and van der Wal 2014). Secondly, object marking is not possible (van der Spuy 1993; Buell 2008; Zeller 2015). Thirdly, there is a close bond between the verb and the post-verbal subject. Evidence for this bond comes from phonological phrasing. In Xhosa, penultimate lengthening indicates the end of a phonological phrase (Jokweni 1995; Downing 2003; Zerbian 2004). An utterance such as in the following example makes up a single phonological phrase, and can be interpreted as in broad focus, meaning that the whole utterance is focused. It is the answer to the question "What are they doing?" Example from Jokweni (1995:31):

$$
\begin{aligned}
& \text { (ba-vúl' incwa:dí) } \\
& \text { 2sM-open 9.book } \\
& \text { 'They open the book. }
\end{aligned}
$$

[Xhosa]

The phrase in (11) can also imply a narrow focus on the object with no change in phonological phrasing. In the case of predicate focus, phrasing is split up. In the following example, the verb is in focus and the object noun is right-dislocated (Jokweni 1995):

$$
\begin{aligned}
& \text { (bá-ya-yi-vú:l') (íncwa:dí) } \\
& \text { 2SM-PRS.DJT-9OM-open 9.book } \\
& \text { 'They open it, as for the book.' }
\end{aligned}
$$

We see this close phonological bond in default agreement inversion, which is a core inversion construction. For example, in (7), the verb and the subject are in one phonological phrase and the penultimate vowel of the verb is not lengthened ${ }^{8}$. This was checked with another speaker, who also pronounces the default agreement inversion construction without lengthening on the verb, as expected:

$$
\begin{aligned}
& \text { ku-khála né-ntá:ka } \\
& \text { 17SM-sing and-10.birds } \\
& \text { 'and the birds were singing...' }
\end{aligned}
$$

[NF160404E]

Further evidence of the close bond between the verb and its inverted subject is provided by the conjoint/disjoint distinction. The Xhosa language exhibits a distinction between the conjoint (short) and disjoint (long) forms of the present and perfect verb forms (van der Spuy 1993; van der Wal and Hyman 2017). The perfect disjoint form with -ile is illustrated in (14) and the conjoint perfect with $-e$ is illustrated in (15):

$$
\begin{aligned}
& \text { i-bá-tháth-i·le ke ya-ba-léqísa } \quad \text { e-síbhedlé:(le) } \\
& \text { 9SM-2OM-take-PRF.DJT then 9SM.PST-2OM-hurry LOC-hospital } \\
& \text { 'it (the ambulance) took them then and hurried them to the hospital.' [BU151210S_b] }
\end{aligned}
$$

\footnotetext{
${ }^{8}$ In this study, vowel length has been measured in Praat by the author, combined with careful listening. However, a systematic, phonetic study of vowel length differences per speaker has not been carried out.
} 


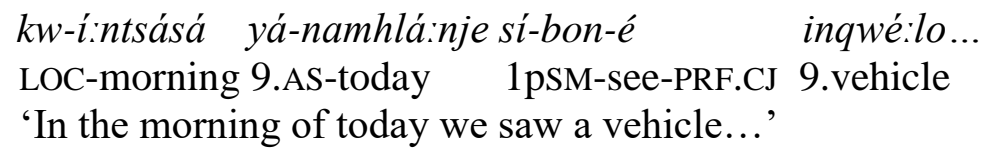

[BU151210S_d]

The same distinction also exists in the present; see (11) and (12). That the distinction between the conjoint and disjoint form relates to information structure and focus has repeatedly been shown for the Bantu language family; see Downing and Hyman (2015) and van der Wal and Hyman (2017) for an overview. This includes other languages of the Nguni group (van der Spuy 1993; Buell 2006) and also Xhosa (Jokweni 1995; Downing 2003; Zerbian 2004). Specifically, the position directly following the conjoint form is important for expressing narrow focus. This position is referred to as the "immediately after verb" (IAV) position, following Watters (1979), and all elements occurring there are verb-phrase internal, as has been shown to be the case in several Bantu languages (e.g. van der Wal 2009; Buell 2009). Question words - being inherently focused - are always in this position, as is the answer to the question. In the following example, ntoni 'what' is in IAV, as is the answer ikati 'cat'; the verb is obligatorily in the conjoint form:

$$
\begin{aligned}
& \text { Q: abantwana ba-léq-á nto:ni? } \\
& \text { 2.children 2SM-chase-FV what } \\
& \text { 'What are the children chasing?' } \\
& \text { A: ba-leq-a iká:ti } \\
& \text { 2SM-chase-FV 9.cat } \\
& \text { 'They are chasing the cat.' }
\end{aligned}
$$

However, the opposite is not necessarily true; not all elements in IAV are in narrow focus. Complements under broad focus also occur in IAV, as is the case with inqwelo 'vehicle' in (15), and ikati 'cat', in an answer where all the information is presented as new:

\section{Q: kwenzeka nto:ni? \\ 'What is happening?'}

A: abantwana bá- léq -a ika:ti

2.children 2SM-chase-FV 9.cat

'The children are chasing the cat.'

[NH150505E]

Therefore, IAV can be said to be the position for non-topical elements, as has been shown for Zulu (Buell 2009). We will come back to these diagnostics in sections 4.2 and 4.3, after analysing the agreeing post-verbal subject in terms of information structure.

The conjoint/disjoint distinction, however, is not relevant in all tenses, and specifically not in the remote past tense, the tense in which most sentences in the narrative are set. We can however try to change the tense of a sentence in elicitation in order to test the distinction between agreeing inversion and agreeing post-verbal subject, as we shall see in section 4.3.

\subsection{Agreeing inversion in Xhosa}

Coming back to agreeing inversion in Xhosa, we see that for (8), repeated here as (18), the postverbal subject ilanga 'sun' is not active or semi-active. The situation is new; after walking for a while, the event of the sun having set is introduced in the story. 


\author{
lâ:-tshona íla:nga \\ 5SM.PST-set 5.sun \\ 'The sun set.'
}

[PSJ150517O]

The same applies to (3), repeated as (19). After being caught by the giant and put into bags for the whole night, the next day is introduced:

$$
\begin{aligned}
& \text { kwâ:sa za-khál(a) inkukhu } \\
& \text { in.the.morning 10SM.PST-cry 10.rooster } \\
& \text { 'In the morning the roosters crowed.' }
\end{aligned}
$$

[PSJ150517O]

Regarding the diagnostics for core inversion constructions, we find that there is no penultimate lengthening of the verb, indicating a close bond between verb and subject. In order to check the agreeing inversion further, a speaker was asked in elicitation whether the phrase in (13) could be changed to replace the default agreement inversion construction. This is possible, and there is no phrase break after the verb:

$$
\begin{aligned}
& \text { za-khála né-nta:ka } \\
& \text { 10SM.PST-sing and-10.birds } \\
& \text { 'and the birds sang.' }
\end{aligned}
$$

[NF160404E]

These first results point to the existence of agreeing post-verbal subject as well as agreeing inversion in Xhosa. If this is correct, examples like (18) and (20) represent agreeing inversion. These have been checked with other speakers and new phrases have been formed through transformational elicitation, with other verbs and subjects. However, agreeing inversion has not shown up spontaneously in elicited examples as the answer to the question "What happened?". This could be due to the question asked: Kwenzeke ntoni? 'What happened?' has noun class 17 agreement, and this could trigger the noun class 17 agreement in default agreement inversion'. Agreeing inversion also does not occur in my data as subject focus. When a subject is questioned, as in Ngubani ogijimayo? 'Who is running?', the answer can be given with a default agreement inversion construction, Kugijima uNontle 'Nontle is running' [BN150927E]. It is possible that agreeing inversion only functions as a thetic expression in Xhosa, and maybe also only as a certain type of thetic expression. More investigation is needed in order to determine the kinds of contexts in which agreeing inversion occurs.

As discussed in section 3.3, an indicator of the close bond between verb and subject in core inversion constructions is the use of a conjoint form. The phrases in the story are mainly expressed in the remote past, where there is no distinction between the conjoint and disjoint form. The perfect form is also used in the story, and in such cases it is the conjoint form that is used:

$$
\begin{aligned}
& \text { ú-th-é úVathíswá } \\
& \text { 1SM-say-PRF Vathiswa } \\
& \text { 'Vathiswa said:' }
\end{aligned}
$$

\footnotetext{
${ }^{9}$ I thank Lutz Marten for pointing this out to me.
} 
The construction occurs several times, but only with the verb $u k u t h i$ 'to say'. This is an irregular verb in Xhosa, which makes it difficult to draw any conclusions regarding the kind of inversion construction this represents. Other verbs were tested with consultants. A conjoint present form is accepted in (22), with the object following the subject. It is assumed that the subject is in focus in this example and that this is agreeing inversion; however, this should be confirmed by looking for similar examples in natural speech. That is also definitely required to establish the VOS order in (23). This phrase is highly unexpected with a conjoint form:

$$
\begin{aligned}
& \text { lí-pheth(a) izim íngxo:wa } \\
& \text { 5SM-close 5.giant 9.bag } \\
& \text { 'The giant closes the bag.' }
\end{aligned}
$$

[NF160404E]

$$
\begin{aligned}
& \text { lí-pheth(a) íngxo:wa í:zîm } \\
& \text { 5sM-close 9.bag 5.giant } \\
& \text { 'The giant closes the bag.' }
\end{aligned}
$$

The example in (20) can also be changed to the present conjoint form. According to the consultant, the last vowel of the verb is obligatorily dropped in such a construction:

$$
\begin{aligned}
& \text { zí-khál' inta:ka } \\
& \text { 10SM-sing 10.birds } \\
& \text { 'The birds are singing.' } \\
& \text { *zikhala iintaka }
\end{aligned}
$$

[SQ160422E]

\section{The function and form of the agreeing post-verbal subject}

We now turn to the constructions in which the subject is dislocated out of the verb phrase. Firstly, information structure will be considered: how the speaker uses this construction in discourse as a referring expression. Secondly, the diagnostics, as introduced in section 3.3, are applied to determine the structure of the phrase. The construction occurs frequently in the narrative in question, a folktale in the oral tradition. It should be noted that most of the examples are in the past, as expected for this genre of speech. Further analysis of other types of spoken language is needed in order to test the ideas presented here. In this section, all examples are from the story [PSJ150517O], unless otherwise indicated.

\subsection{Information structure in "The two girls who escaped from a giant"}

The story starts with a default agreement inversion construction. As already mentioned in section 3.1, this is a strategy frequently used to introduce new information, where both the subject and the predicate are in focus, referred to as a "thetic sentence" or "sentence focus" (Lambrecht 2000):

$$
\begin{aligned}
& \text { kwá-kú-ngu-mâ:ma ó-wá-yé-ná-mántombazana áma-bi:ní } \\
& \text { 17SM.PST-17SM.CT-COP-1a.mother 1RC-1SM.PST-1SM.CT-with-6.girls 6AC-two } \\
& \text { 'There was a mother who had two daughters.' }
\end{aligned}
$$


The daughters introduced in (25) are now the active concept about which the following statement is made. After this, the concept 'mother' is picked up again. In order to do this, the subject umama 'mother' follows the verb:

wá:-wá-yálela: ké uma:ma índlela é:-ya kwa-malû:me

1SM.PST-6OM-instruct then 1a.mother 9.road 9.RC-go LOC-1a.uncle

'The mother then explained to them the way to get to uncle.'

After she has explained how to get there, an agreeing post-verbal subject construction is used again to refer to the girls. This pattern repeats itself throughout the story, in a manner that I propose is related to the pragmatic states of the referents, as introduced in section 3.2. The concepts have been previously mentioned in discourse and can be said to be semi-active or accessible. To bring them into an active state, either the agreeing post-verbal subject construction is used or some other non-canonical construction (for example 'they went while their mother said goodbye', with a switch to mother as active concept). When a concept has been brought into the active state, a few sentences (normally one to four) refer to the active concept, until it changes to another.

The agreeing post-verbal subject construction is also common when introducing and changing the utterer of direct speech. This is called "quotative inversion":

$$
\begin{aligned}
& \text { wáth(i) úNóntsókólo: } \\
& \text { 1SM.PST-say Nontsokolo } \\
& \text { 'Nontsokolo said:' }
\end{aligned}
$$

Because of its function of changing a semi-active concept to the active concept in the story, transitions from one event to another are also often marked by means of the agreeing postverbal subject construction. For example, after discussing for a long time what road to take, the construction is used when someone finally makes a move:

$$
\begin{aligned}
& \text { wâ:-thatha é-ya-sé-kunene uNontsokolo... } \\
& \text { 1SM.PST-take 9.RC-9AS-LOC-right Nontsokolo } \\
& \text { 'Nontsokolo took the right one (road).' }
\end{aligned}
$$

Inactive concepts are not introduced by this construction. When the giant comes into the picture, it is as the complement of a verb: 'they heard the growling of a giant'. After this introduction, the actions of the giant are often introduced with the agreeing post-verbal subject construction, which brings the concept 'giant' into the picture and turns it into an active concept again. Two examples are the following:

l-othúk(a) izi:m, lá:-vúka lá-hlála ng-éempu:ndu

5SM.PST-be.startled 5.ogre 5SM.PST-wake.up 5SM.PST-sit with-10.buttocks 'the ogre got startled, woke up and sat on his buttocks.'

$$
\text { lâ:-fí:k(a) izi:m lá-vál(a) e-mnyá:ngo }
$$

5SM.PST-arrive 5.giant 5SM.PST-open LOC-3.doorway

'The giant arrived and opened the door.' 
This construction, therefore, is used to re-activate an accessible concept, which becomes the topic of the sentence. It is interesting to note that due to variation in phonological phrasing, the agreeing post-verbal subject construction appears morphosyntactically similar to agreeing inversion. Recall from section 3.2 that agreeing inversion is a core inversion construction used for thetic sentences or for subject focus. Apart from this function, it is characterised by diagnostics relating to the close bond between the verb and the subject. In order to establish the properties of agreeing post-verbal subject and the differences between this and agreeing inversion, it is necessary to go into more detail regarding the diagnostics that are used to establish if a subject is dislocated or if there is a close bond between the verb and the subject.

\subsection{Agreeing post-verbal subject and phonological phrasing}

As shown in section 3.3, a strong indication of a phonological phrase in Xhosa is penultimate lengthening (Jokweni 1995; Downing 2003; Zerbian 2004). The end of a phonological phrase following the predicate indicates that what appears after that phonological phrase is dislocated. In the examples in the story, we find utterances where the subject is dislocated, in the sense that it is preceded by a verb with penultimate lengthening.

la-go:dû:k(a) izim

5SM.PST-go.home 5.giant

'The giant went home.'

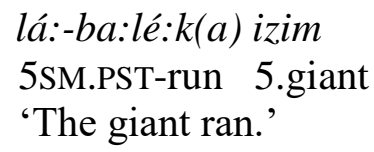

In many other cases, however, there is no penultimate lengthening. We see this in (29), and also in the following:

$$
\begin{array}{ll}
\text { bâ:-zo-phúm(a) ábantwana kw-ézi } & \text { ngxo:wa } \\
\text { 2SM-FUT-come.out 2.children LOC-10.DEM.PRX 10.bag } \\
\text { 'The children will come out through these holes.' }
\end{array}
$$

This is unexpected. It should be noted that this narrative is told by an amateur storyteller, but a very talented and charismatic one. Therefore, the intonation is sometimes marked with high pitches and other ways of making the story sound even more interesting to the children. Lengthening is sometimes also exaggerated for such purposes, as is the case in (32). In order to test the lengthening of agreeing post-verbal subject phrases further, the same sentences were pronounced by another speaker, as mentioned in section 2. For many of the phrases taken from the text, the speaker accepts a version with vowel liason, as well as a more carefully pronounced version where the vowel remains. The penultimate vowel, however, remains short:

$$
\begin{aligned}
& \text { lâ-súkum' í:zim } \\
& \text { lâ-súkuma í:zim } \\
& \text { 5SM.PST-stand.up 5.giant } \\
& \text { 'the giant stood up.' }
\end{aligned}
$$

[NF160404E] 
As there is no penultimate lengthening on the verb, the verb and the subject can be considered to be in the same phonological phrase. When changed to a present disjoint form, there is a clear phrase break after the verb. The present conjoint form is disallowed in this specific case:

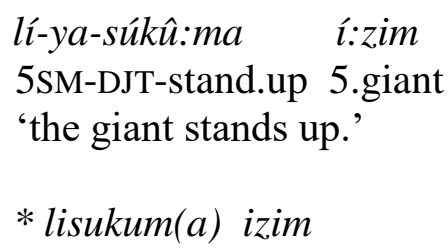

[NF160404E]

It could be that this kind of phonological phrasing is specific to the past. In summary, the penultimate vowel of the verb followed by the subject is sometimes lengthened, and sometimes is not. It appears that the relationship between phonological phrasing and syntactic phrasing is an imperfect one. This is also shown in a recent paper on phrasing in Zulu, in which penultimate lengthening was systematically measured in verbs followed by an in situ direct object or a dislocated object in tense forms without the conjoint/disjoint alternation (remote past and future) (Zeller, Zerbian and Cook 2017). When comparing the length of penultimate vowels across the whole sample of tokens per speaker, penultimate lengthening is a relevant and significant indicator of phonological phrasing. However, not all penultimate vowels are lengthened in the relevant contexts. Medial and final vowels differ more clearly in their length in the morphologically marked present forms, but show some overlap in the remote past. This means that there is some variation in the length of penultimate lengthened vowels, and this variation is greater for some speakers than for others.

Although these findings concern Zulu and are not related to subject inversion constructions, they give an indication of why penultimate lengthening is not always crystal clear. In measuring vowels in an utterance, it is fairly easy to distinguish between a short and a lengthened vowel. But in many instances, a vowel may be slightly longer than a short one would be, but is not a clearly lengthened vowel. As vowel lengthening is important for our understanding of phonological phrasing and morphosyntactic structure, a detailed analysis of the phonetic properties of vowel lengthening in Xhosa would be much needed. We now turn to other diagnostics of dislocation, as introduced in section 3.3.

\subsection{Other diagnostics of dislocation}

The first diagnostic concerns the omission of the subject. This is allowed in terms of the morphosyntactic structure of the agreeing post-verbal subject construction, according to my consultant (although it might make the story less clear). As the omission of the subject in the following example is based on (34), we can conclude that it is the post-verbal rather than a preverbal subject that is left out:

$$
\begin{aligned}
& \text { lá-súkú:ma } \\
& \text { 5SM.PST-stand.up } \\
& \text { '(the giant) stood up.' }
\end{aligned}
$$

Secondly, the occurrence of an object marker is evidence of dislocation. There is no example of an agreeing post-verbal subject with an object marker in the text. However, the language consultant accepts adding an overt post-verbal subject to a construction with an object marker 
from the text. In the original text, izim 'giant' does not follow the verb, but it has been added in the example:

$$
\begin{aligned}
& \text { lá-m-fák(a) izim } \\
& \text { 5SM.PST-1OM-put } \\
& \text { 'The giant put her (inside).' }
\end{aligned}
$$

[NF160404E]

The consultant also accepts this construction without the deletion of the last vowel of the verb. In her pronunciation, the penultimate vowel is now lengthened:

$$
\begin{aligned}
& \text { lá-m-fá:ka í:zim } \\
& \text { 5sM.PST-1OM-put 5.giant } \\
& \text { 'The giant put her (inside).' }
\end{aligned}
$$

[NF160404E]

Also, an adverb can intervene between the verb and the subject. In the case of core subject inversion, this is not possible, as the subject has to appear in IAV:

$$
\begin{aligned}
& \text { lá-m-fák(a) é-ngxow-é:ni om-nye i:zim } \\
& \text { 5SM.PST-1OM-put LOC-9.bag-LOC 1AC-one 5.giant } \\
& \text { 'The giant put one of them in the bag.' }
\end{aligned}
$$

[NF160404E]

All this clearly points to a dislocated subject, and, in such cases at least, the VS constructions in the story are not agreeing inversion but involve a dislocated subject, however confusing the phonological phrasing seems. Another diagnostic related to the close bond between verb and subject is the conjoint/disjoint distinction. In elicitation, agreeing post-verbal subject constructions with a right-dislocated subject are easily elicited by asking a question about the action (see also (35)):

$$
\begin{aligned}
& \text { Q: benza ntoni? 'What are they doing?' (the children) } \\
& \text { A: bá-yá-dla:l-a abántwa:na } \\
& \text { 2SM-PRS.DJT-play-FV 2.children } \\
& \text { 'they are playing, the children.' }
\end{aligned}
$$

[NF151210E]

As we can see from the use of the disjoint form and the phonological phrasing, the subject abantwana 'children' is outside of the verb phrase and is right-dislocated. The subject is therefore in a non-focused position, as has been pointed out for Zulu (Buell 2008). The subject is the topic and there is predicate focus.

\section{Concluding remarks}

This paper has examined constructions in which the subject follows the verb in a narrative in Xhosa. These inverted constructions are of three kinds in the narrative. One of these is default agreeing inversion, whereby a default agreement marker $k u$ - is used with the conjoint form of the verb and is followed by the subject immediately after the verb in the same verb phrase. Such constructions are commonly used to introduce a new situation and can also be found in the narrative. Surprisingly, constructions in which the verb agrees with the post-verbal subject are also found in this narrative with the same kind of function, i.e. as thetic sentences. These constructions were tested in elicitation and this paper concludes that Xhosa makes use of 
agreeing inversion, although this has not previously been attested for this language, nor for other Nguni languages. In agreeing inversion, the post-verbal subject is phonologically phrased with the verb and is not dislocated. However, these conclusions are drawn based on limited data and need to be tested further in future research.

In the most commonly used inversion construction in the narrative, the subject is - in contrast to the agreeing inversion construction - dislocated out of the verb phrase, as evidenced by penultimate lengthening on the verb. It is concluded that this construction is used when the concept denoted by the subject is semi-active; i.e. it has been mentioned previously in the text or it can be inferred from the context. The agreeing post-verbal subject construction is therefore commonly used when something new happens in the story and it needs to be made clear who the agent of the action is. It appears frequently in turn-taking; i.e. to change the person who is saying something in the narrative. However, the diagnostics used in Bantu language studies to determine the dislocation of the subject are not always in place, specifically with regard to penultimate lengthening. In several of the sentences in the narrative, there is no lengthening of the penultimate vowel of the verb preceding the subject. These sentences make use of the remote past form of the verb. This result fits in nicely with recent findings with regard to penultimate lengthening in closely-related Zulu, for which it has been concluded that such lengthening is not a clear sign of phonological phrasing in the tenses that do not have a morphological distinction between the conjoint and the disjoint forms, such as the remote past.

\section{References}

Bresnan, J. and J. M. Kanerva. 1989. Locative inversion in Chichewa: A case study in factorization in grammar. Linguistic Inquiry 20(1): 1-50.

Buell, L. 2006. The Zulu conjoint/disjoint verb alternation: Focus or constituency? ZAS Papers in Linguistics 43: 9-30.

Buell, L. 2007. Semantic and formal locatives: Implications for the Bantu locative inversion typology. SOAS Working Papers in Linguistics: 105-120.

Buell, L. 2008. VP-internal DPs and right-dislocation in Zulu. In M. van Koppen and B. Botma (eds.) Linguistics in the Netherlands 25. Amsterdam: John Benjamins. pp. 37-49.

Buell, L. 2009. Evaluating the immediate postverbal position as a focus position in Zulu. In M. Matondo et al. (eds.) Selected Proceedings of the $38^{\text {th }}$ Annual Conference on African Linguistics. Somerville, MA: Cascadilla Proceedings Project. pp. 166-172.

Carstens, V. and L. Mletshe. 2015. Radical defectivity: Implications of Xhosa expletive constructions. Linguistic Inquiry 46(2): 187-242.

Chafe, W. 1976. Givenness, contrastiveness, definiteness, subjects and topics. In C. N. Li (ed.) Subject and topic. New York: Academic Press. pp. 27-55

Chafe, W. 1987. Cognitive constraints on information flow. In R. Tomlin (ed.) Coherence and grounding in discourse. Amsterdam: John Benjamins.

Creissels, D. 2011. Tswana locatives and their status in the inversion construction. Africana Linguistica 17: 33-52. 
Demuth, K. 1990. Locatives, impersonals and expletives in Sesotho. The Linguistic Review 7: 233 249.

Demuth, K. and S. Mmusi. 1997. Presentational focus and thematic structure in comparative Bantu. Journal of African Languages and Linguistics 18: 1-19.

Doke, C. M. 1954. The Southern Bantu languages. London: Oxford University Press for the International African Institute (IAI).

Downing, L. J. 2003. Stress, tone and focus in Chichewa and Xhosa. In R.-J. Anyanwu (ed.) Stress and tone - The African experience. Köln: Rüdiger Köppe Verlag.

Downing, L. J. and L. M. Hyman. 2015. Information structure in Bantu. In C. Féry and S. Ishihara (eds.) The Oxford handbook of information structure. Oxford: Oxford University Press.

du Plessis, J. A. and M. W. Visser. 1992. Xhosa syntax. Johannesburg: Afrikaanse Pers-Boekhandel.

Gundel, J. K., N. Hedberg and R. Zacharski. 1993. Cognitive status and the form of referring expressions in discourse. Language 69(2): 274-307.

Jokweni, M. W. 1995. Aspects of isiXhosa phrasal phonology. Doctoral dissertation. Illinois: University of Illinois, Urbana-Champaign.

Krifka, M. 2006. Basic notions of information structure. In C. Fery and M. Krifka (eds.) Interdisciplinary studies on information structure 6. Potsdam: Universitätsverlag. pp. 13-56.

Lambrecht, K. 1994. Information structure and sentence form: Topic, focus, and the mental representations of discourse referents. Cambridge: Cambridge University Press.

Lambrecht, K. 2000. When subjects behave like objects. Studies in Language 24(3): 611-682.

Marten, Lutz. 2006. Locative inversion in Otjiherero: More on morpho-syntactic variation in Bantu. ZAS Papers in Linguistics 43: 97-122.

Marten, Lutz. 2011. Information structure and agreement: Subjects and subject markers in Swahili and Herero. Lingua 121(5): 787-804.

Marten, L. and J. van der Wal. 2014. A typology of Bantu subject inversion. Linguistic Variation 14(2): 318-368.

Nobuko, Y. 2011. Word order in Matengo (N13): Topicality and informational roles. Lingua 121(5): 754-771.

Nyamende, A. 1994. Regional variation in Xhosa. Stellenbosch Papers in Linguistics Plus 26: 202217.

Sasse, H.-J. 1996. Theicity. Cologne: Institut für Sprachwissenschaft der Universität zu Köln. van der Spuy, A. 1993. Dislocated noun phrases in Nguni. Lingua 90: 335-355

van der Wal, J. 2008. Agreement in thetic VS sentences in Bantu and Romance. In C. De Cat and K. Demuth (eds.) The Bantu-Romance connection: A comparative investigation of verbal agreement, DPs, and information structure. Amsterdam: John Benjamins Publishing Company. pp. 323-350 
van der Wal, J. 2009. Word order and information structure in Mahkuwa-Enahara. Doctoral dissertation. Leiden: Universiteit Leiden.

van der Wal, J. and L. M. Hyman. 2017. The conjoint/disjoint alternation in Bantu. Berlin: De Gruyter.

Watters, J. 1979. Focus in Aghem. In L. M. Hyman (ed.) Aghem grammatical structure. Los Angeles: University of Southern California. pp. 137-197.

Zeller, J. 2013. Locative inversion in Bantu and predication. Linguistics 51(6): 1107-1146.

Zeller, J. 2015. Argument prominence and agreement: Explaining an unexpected object asymmetry in Zulu. Lingua 156: 17-39.

Zeller, J., S. Zerbian and T. Cook. 2017. Prosodic evidence for syntactic phrasing in Zulu. In J. van der Wal and L. M. Hyman (eds.) The conjoint/disjoint alternation in Bantu, Berlin: De Gruyter.

Zerbian, S. 2004. Phonological phrases in Xhosa (Southern Bantu). ZAS Papers in Linguistics 37: 7199.

Zerbian, S. 2006. Expression of information structure in Northern Sotho. Doctoral dissertation. Berlin: Humboldt University. 


\title{
Appendix
}

\section{"The two girls who escaped from a giant" (or: "Always listen to your mother")}

\author{
Narrated by Nomawethu Wole Nkwaqa ${ }^{10}$
}

$\begin{array}{lll}\text { kwa-ku-ngu-mama } & 11 & \text { o-wa-ye-na-mantombazana ama-bini.Ng-enye imini } \\ \text { 17PST-17CT-COP-1a.mother } & \text { 1RC-1PST-1CT-CONN-6.girls 6AC-two INSTR-one 9.day }\end{array}$

la mantombazana, a-cela ${ }^{12}$ uku-ya ku-lo malume. Wa-wa-yalela

6.DEM.PRX 6.girls 6PST-beg INF-go 17LOC-DEM.PRX 1a.uncle 1PST-6OM-instruct

ke umama indlela e-ya kwa-malume; "ukuba ni-za-wul'-hamba

then 1a.mother 9.road 9REL-go LOC-1a.uncle that 2pSM-FUT-3OM-walk

e-kudiban-eni kwe-ndlela ni-zo-bona iindlela ezim-bini ezo-hlukene-yo;

LOC-to.meet-LOC 17AS-road 2pSM-FUT-see 10.road 10AC-two 10REL-separate-REL

e-nye i-bheka nga-se-kunene, e-nye i-bheka nga-se-kunxele”. A-zi-lungiselela

9AC-one 9-go.to INSTR-LOC-right 9-one 9.go.to INSTR-LOC-left 6PST-REFL.prepare.for

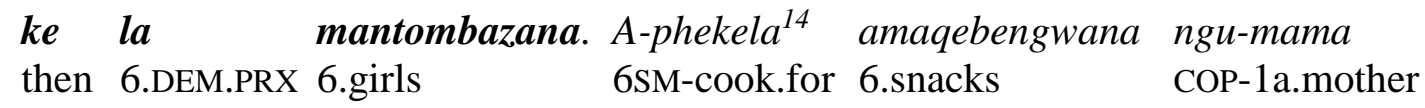

wawo, wa-xhela ne-nkukhu, khon $\left(a^{15}\right)$ ukuze ba-thi $\quad x a$

1.their(cl.6)1 $1 \mathrm{PST}^{16}$-slaughter CONN-9.chicken so.that 2SM-say when

be-lamb-ile e-ndlel-eni ba-ty-e. Ba-zi-lungiselela nge-mivuyo,

2PRT-be.hungry-PRF LOC-9.road-LOC 2SM-eat-SBJV 2PST-REFL-prepare.for INSTR-4.joy

\footnotetext{
${ }^{10}$ Transcription, translation, and glossing is a long and repetitive process, and I would like to thank the following people for assistance in this task: Nozibele Nomdebevana, Thembani Ma'at Onceya, Sikelelwa Qwazi, Onelisa Mcimbi, and Stefan Savič. Remaining mistakes and shortcomings in glossing are my own.

${ }^{11}$ The glossing abbreviations are as follows: numbers 1, 2, etc. refer to noun class numbers. AC=adjectival

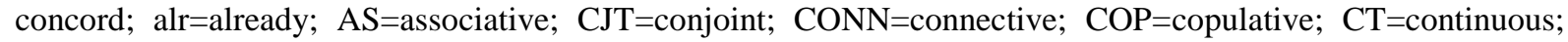
$\mathrm{DEM}=$ demonstrative; DIM=diminutive; DST=distal; DJT=disjoint; EMPH=the negative used as emphatic; FUT=future; HRT=hortative; INF=infinitive; INSTR=instrumental nga- (used for a variety of meanings, not only instrument); IT=itive; LOC=locative; $\mathrm{NEG=negative;} \mathrm{OM}=$ object marker; $\mathrm{p}=$ plural; $\mathrm{PL}=$ plural imperative; $\mathrm{PRF}=$ perfect; pro=pronoun; PRT=participial; PRX=proximal; PST=past; RC=relative concord; REC=recent; $\mathrm{RECP}=$ reciprocal; REF=referential demonstrative; REFL=reflexive; REL=relative; RM=remote; $\mathrm{s}=$ singular; SBJV=subjunctive; SM=subject marker (only marked in present; markers PST, PRT, NEG and CT imply SM).

${ }^{12}$ The final vowel forms part of the inflection of a Xhosa verb. For example, past in the example wa-wa-yalel-a 'she commanded them' is indicated in the first $a$ of the subject marker wa-, and the last $a$ of the final vowel. In the perfect, the final vowel is $-e$. In this text, I do not gloss the final vowel $-a$ separately, as it is the most commonly used final vowel here.

${ }^{13}$ The infinitive $k u$ - is expected here (Onelisa Mcimbi, p.c.).

${ }^{14}$ This is most probably a mistake, according to the transcriber, and should be a passive: aphekelwa.

15 The text has to some extent been transcribed according to conventions based on Allwood and Hendrikse (2005). Parentheses indicate that the vowel or some other element is not heard. A plus sign (+) indicates that the word is not finished (self-correction or stuttering). Tone has not been marked.

${ }^{16}$ The second and subsequent actions in a sequence of actions in the past is expressed by the past subjunctive. The only distinction between the past and the past subjunctive is tonal. In this glossing the distinction is not indicated.
} 
ngoba ba-be-qala kwa-ku-lusuku lwabo lo-ku-qala uku-yo ${ }^{17}$-bona because 2PST-2CT-begin 17PST-17CT-11.day 11.their 11AS-INF-first INF-IT-see

umalume. Ba-vuka ngentseni, ba-lungisa ba-zi-hlamba ba-thatha 1a.uncle 2PST-wake.up at.dawn 2PST-prepare 2PST-REFL-wash 2PST-take

iibheg-ana zabo ba-faka iimpahla zabo. Enye ya-yi-n-dala enye 10.bag-DIM 10.their 2PST-put 10.clothes 10.their 9.one 9PST-9COP-9NCP-old 9.one

i-ncinane kunenye. Ba-hambake umama wabo e-ba-bhabhayisa, 9AC-small than.the.other 2PST-walk then 1a.mother 1.their 1.PRT-2OM-say.goodbye.to

"bhabhay-ini bantwanani-hamb-e kakuhle. Ni-khumbul-e ke ingakumbi bye-PL 2.children 2pSM-walk-SBJV well 2pSM-remember-SBJV then especially

wena Nontsokolo, ni-thath-e indlela ya-se-kunxele Ni-nga-yi-thath(i)

you Nontsokolo 2pSM-take-SBJV 9.road 9AS-LOC-left 2pSM-NEG-9OM-take-NEG

indlela ya-se-kunene, i-za-ku-ni-lahlekisa."

9.road 9AS-LOC-right 9SM-FUT-INF-2pOM-make.disappear owu 2PST-agree 2.children

"Ewe mama!". Ba-hamba ke b-onwab-ile. Be-hamb-e be-taka-taka, yes mother 2PST-walk then 2SM-be.happy-PRF 2PRT-walk-PRF 2PRT-jump-jump

be-vuya be-cof-ana, "Yho! si-za-ku-ya kwa-malume! Thyini

2PRT-be.happy 2PRT-touch-RECP yho 1pSM-FUT-INF-go LOC-1a.uncle goodness

si-za-wul19-bona umalume." La-tshona ilanga. Ba-thi xa be-fika

1pSM-FUT-3OM-see 1a.uncle 5PST-set 5.sun 2PST-say when 2PRT-arrive

kwe-zaa ndlela zi-mbini zo-hlukile-yo enye i-tshona

LOC-10.DEM.DST 10.road 10AC-two 10REL-separate-REL 9.one 9SM-disappear

nga-se-kunene, enye i-tshona nga-se-kunxele ba-fik-e be-ma.

INSTR-LOC-right 9.one 9SM-disappear INSTR-LOC-left 2SM-arrive-PRF 2PRT-stop

U-th-e lo u-mncinane, "Nontsokolo u-beth-e umama kanene

1SM-say-PRF 1.DEM.PRX 1.small.one Nontsokolo 1SM-instruct-PRF 1a.mother really

si-thath-e e-yiphi indlela,si-hamb-e ng-e-yiph(i) indlela”.

1pSM-take-SBJV 9RC-9.which 9.road 1pSM-walk-SBJV INSTR-9RC-9.which 9.road

\footnotetext{
${ }^{17}$ Judging by the examples in this text, this prefix is hypothesised to be an itive, but further research is needed.

${ }^{18}$ Sounds and ideophones used by the narrator are not translated. For example, zum is used for the sound and idea of quickly getting into water, from ukuzumka 'sink in water'. Such ideophones are often preceded by (an inflected version of) $u k u t h i$ 'to say'. Some are translated, like lozi, which indicates the flickering of lights. The ideophone phofu is added to express surprise. The word kanti is added to express contrast and/or surprise.

${ }^{19}$ It is unclear why wu-, the object marker of noun class 3 , is used here. If it would refer to umalume in noun class $1 \mathrm{a}$, the object marker is expected to be $m$-.
} 
U-th-e uNontsokolo "umamae-beth-e si-hamb-e nge-ya-se-kunene". 1SM-say-PRF Nontsokolo 1a.mother 1PRT-instruct-PRF1pSM-walk-SBJV INSTR-9AS-LOC-right

Yho, uVathiswa a-ka-zange a-yi-vume no-ku-yi-vuma

yho Vathiswa NEG-1NEG-never NEG-9NEG-agree CONN-INF-9OM-agree

loo nto leyo. Wa-thi "hayi Nontsokolo, umam(a) e-beth-e 9.DEM.REF 9.thing 9.DEM.REF 1PST-say no Nontsokolo 1a.mother 1PRT-instruct-PRF

si-thath(-e) indlela ya-se-kunxele, si-nga-yi-thath-(i) e-ya-se-kunene”.

1pSM-take-SBJV 9.road 9AS-LOC-left 1pSM-NEG-9OM-take-NEG 9RC-9AS-LOC-right

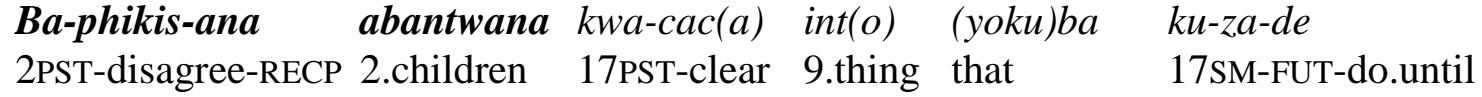

ku-rhatyel-e be-phikis-ana. Wa-thatha e-ya-se-kunene uNontsokolo

17SM-dusk-PRF 2PRT-disagree-RECP 1PST-take 9RC-9AS-LOC-right Nontsokolo

ngoba ya-yi-ngu-ye om-dala. Kwa-y-e kwa-nyanzeleka

because 9PST-9COP-COP-she 1AC-old 17PST-come-PRF 17PST-have.no.alternative

into yokokubana no-Vathiswa lo umncinci a-landel-e

9.thing that CONN-Vathiswa 1.DEM.PRX 1.small 1SBJV-follow-SBJV

uNontsokolo, ba-hamb-e nge-ndlela ya-se-kunene, ebe-kuthwe

Nontsokolo 2PST-walk-PRF INSTR-road 9AS-LOC-right 1CT.REC.PST-told.PASS

ba-nga-hamb-i nga-yo ngoba i-za-ku-ba-lahlekisa. $\quad$ Ba-hamb-ile,

2SM-NEG-walk-NEG INSTR-9.it because 9SM-FUT-INF-2OM-make.disappear 2PST-walk-PRF

ba-hamba, ba-hamba, ba-ngena e-hlath-ini. Ndi-xelel-eni

2PST-walk 2PST-walk 2PST-enter LOC-5.forest-LOC 1OM-tell-SBJV.PL

ke bantwana bam uku-ngena kwa-bantwana e-hlath-ini ilanga li-tshon-ile,

then 2.children 2.my INF-enter 15AS-2.children LOC-5.forest-LOC 5.sun 5SM-set-PRF

be-nga-z-az-i nokokubana ba-za uku-fika na kwa-malume.

2CT-NEG-REFL-know-NEG that 2SM-FUT INF-arrive quest LOC-1a.uncle

Yho, imithi ya-yi-shukuma, ngoba kaloku izilwanyana za-se-hlath-ini

yho 4.tree 4PST-4CT-shake because because 10.animal 10AS-LOC-5.forest-LOC

zi-zam(a) uku-lala nge-li xesha. Ku-khala n-eentaka, zi-zam(a)

10SM-try INF-sleep INSTR-5.DEM.PRX 5.time 17SM-sing CONN-10.bird 10SM-try

uku-thi 'tyululukuthu, tyululuthuku' Yho! Iinkawu: 'tyo! tyo!, tyo!' Yho!

INF-say 'tyululukuthu, tyululuthuku' Yho! 10.monkey 'tyo! tyo! tyo!' yho 


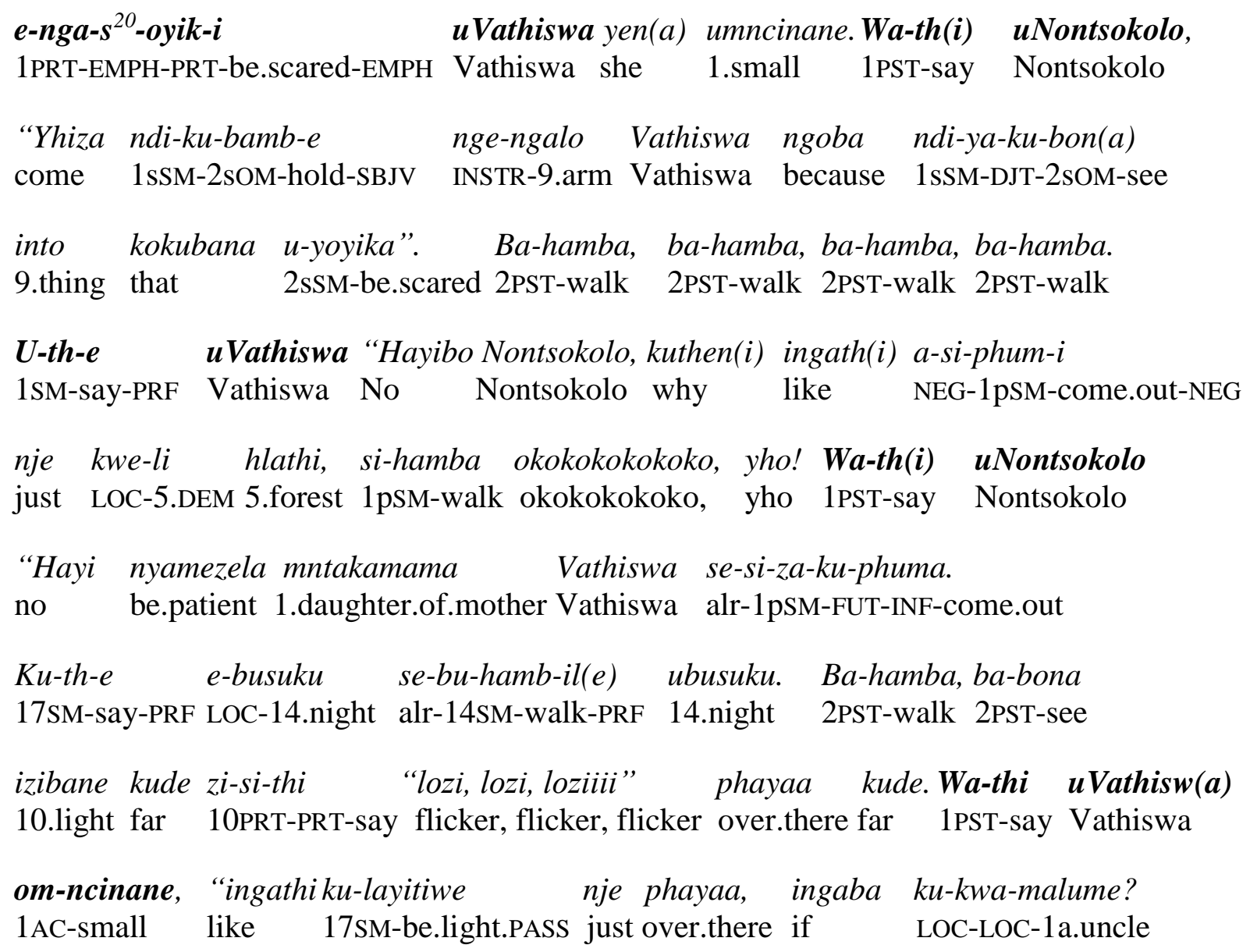

U-the uNontsokolo, "Ewe, se-si-za-ku-fika." Ba-hamba, ba-hamba, 1SM-say-PRF Nontsokolo yes alr-1pSM-FUT-INF-arrive 2PST-walk 2PST-walk

ba-hamba ba-de ba-phuma ngaphandle. Ba-th-e xa 2PST-walk 2PST-do.until 2PST-come.out outside 2SM-say-PRF when

be-ku-sondela nga-ku-lo 3.mzi u-layitile-yo, be-va 2PRT-LOC-approach INSTR-LOC-3.DEM.PRX 3.homestead 3REL-light-REL 2PST-hear umgqumo we-zim phofu li-y-ozela li-lel-e nga-se-mnyango 3.growling 3AS-5.giant phofu 5SM-DJT-be.drowsy 5SM-sleep-PRF INSTR-LOC-doorway

li-diniwe, be-li-yo-zingela nants(i) ingxowa ya-lo e-cal-eni 5SM-be.tired CT-5SM-IT-hunt here 9.bag 9AS-5DEM.PRX LOC-5.side-LOC

kwa-lo. Yho! li-thi-n(i) izim “hee yhee phephephe! "Hayi umoyiko om-ngako LOC-DEM.PRX yho 5SM-say-what 5.giant'hee yhee phephephe no 3.fear 3AC-such ka-Vathiswa "Yho! Nontsokolo! Si-za-ku-thini si-za-ku-tyiwa le-zim of-Vathiswa yho Nontsokolo 1pSM-FUT-INF-do.what 1pSM-FUT-INF-eat.pass 5AS-giant

\footnotetext{
${ }^{20}$ A prefix $s i$ - is added in the participial before monosyllabic stems, and $s$ - before vowel-initial stems. It is glossed as PRT=participial.
} 
nje". U-the xa esi-tsho l-othuk(a) izim, la-vuka la-hlala just 1SM-say-PRF when 1PRT-say.so 5PST-be.startled 5.giant 5PST-wake.up 5PST-sit ng-eempundu, la-thi "ffakatha,ffakatha, kwangathi ku-nuka ivumba lo-mntu INSTR-10.buttocks 5PST-say ffakatha ffakatha why 17SM-smell 5.smell 5AS-1.person nje apha? ffakatha,ffakatha, kwangathi ku-nuka ivumbalo-mntu nje just here ffakatha, ffakatha why 17sM-smell5.smell 5AS-1.person just apha”. Yho! w-oyika no-Nontsokolo ngoku em-dala,wa-thi "yho! here yho 1PST-be.scared CONN-Nontsokolo now 9AC-old 1PST-say yho $\begin{array}{llllll}\text { Umama } & \text { ebe-tshilo } & \text { wa-thi } & \text { si-nga-hamb-i } & \text { nga-le } & \text { ndlela”. } \\ \text { 1a.mother } & \text { 1CT.REC.PST-say } & \text { 1PST-say } & \text { 1pSM-NEG-walk-NEG } & \text { INSTR-9.DEM.PRX } & \text { 9.road }\end{array}$

Yho! La-sukuma izim, la-xhuma la-ba-bamba bobabini. yho 5PST-stand.up 5.giant 5PST-jump 5PST-2OM-catch both

La-m-fak(a) e-ngxow-eni $\quad$ om-(nye), kant(i) ezi $\quad$ ngxowa $\quad$ zim-bini. 5PST-1OM-put LOC-9.bag-LOC 1AC-one kanti 10.DEM.PRX 10.bag 10AC-two

La-fak(a) uVathiswa ngapha, lafak(a) uNontsokolo ngapha. Phof(u) ingxowa 5PST-put Vathiswa this.side 5PST-put Nontsokolo this.side phofu 5.bag li-yi-vul-e imingxuma enze(le uk)ubaba-zo-kwaz(i) uku-phefumla. La-yi-qhin(a) 5SM-4OM-open-PRF 4.holes so.that 2SM-FUT-be.able INF-breath 5PST-9OM-tie ingxowa, la-yi-qhin(a) ingxowa, la-ba-gcina. Lathi, "Ni-ya-bona, 9.bag 5PST-9OM-tie 9.bag 5PST-2OM-guard 5PST-say 2pSM-DJT-see ndi-zo-ni-tya mhla iimvula za-magqabagqab-ana”. Yho, a-ba-s-oyik-i 1sSM-FUT-2pOM-eat when 10.rain 10PST-6.drops-DIM yho EMPH-2SM-PRT-be.scared-EMPH e-ngxow-eni, aba-s-oyik-i e-ngxow-eni. La-lal(a) izim LOC-9.bag-LOC EMPH-2SM-PRT-be.scared-EMPH LOC-5.bag-LOC 5PST-sleep 5.giant e-busuku, phofu li-lala li-zi-bamb-il(e) ezi ngxowa, li-funa LOC-14.night phofu 5SM-sleep 5PRT-10OM-hold-PRF 10.DEM.PRX 10.bags 5SM-want ba-nga-phum-i kwe-zi ngxowa. Iyho, kwasa za-khal(a) 2SM-NEG-come.out-NEG LOC-10.DEM.PRX 10.bags yho in.the.morning 10PST-crow

iinkukhu, kurukugu!!!! Iyho! Ekuseni la-vuka izim la-yo-funa 10.rooster kurukugu yho in.the.morning 5PST-wake.up 5.giant 5PST-IT-want

amanzi apho a-nga-khona. Kanti li-za-wu-dlula nga-se-mz-ini apho 6.water there 6SM-may-be kanti 5SM-FUT-3OM-pass INSTR-LOC-3.homestead-LOC there ku-xhelwe khona inkomo. La-bizwa, "Khawu-z-e, khawu-z-e 17SM-slaughter.PASS there 9.cattle 5SM-call.PASS 2sHRT-come-SBJV 2sHRT-come-SBJV 
ngapha mfondini, si-ku-sikel-(e) inyama", la-dlul(a) izim e-mz-ini

here 1.my.friend 1pSM-2sOM-cut-SBJV 9.meat 5PST-pass 5.giant LOC-3.homestead-LOC

li-pheth-(e) ezi ngxowa, li-ya-vuma, gqu, gqu, gqu, gqu. La-fika

5PRT-close-PRF 10.DEM.PRX 10.bags 5SM-DJT-agree gqu gqu gqu gqu 5PST-arrive

la-zi-beka phantsi iingxowa. Kwa-thwa "khawu-bamb-(e) apha khe

5PST-10OM-put down 10.bags 17PST-tell.pass 2sHRT-take-SBJV here HRT

si-ku-galelel-(e) intweselwayo”. La-sela hi-i-hi-i-hi-i kantiabantu ba-krokrel(a) 1pSM-2SOM-pour-SBJV 9.thing.to.drink 5PST-drink hi-i hi-i hi-i kanti 2.person 2PST-suspect

ubangathi ku-khon(a)abantu kwe-zi ngxowa. Ba-li-thuma ba-thi that 17SM-be 2.person LOC-10.DEM.PRX 10.bags 2SM-5OM-send 2SM-say

ma-li-hamb-e li-yo-( $\left(\mathrm{u}^{2}{ }^{21}\right) k h a$ amanzi. U-th-e om-nye umfo apha

HRT-5SM-go-SBJV 5SM-IT-INF-draw 6.water 1SM-say-PRF 1AC-one 1.man here

"ndi-za-zi-gcin(a) ezi ngxowa zakho a(ku)kho mnt(u) u-zo-zi-thatha.

1sSM-FUT-10OM-keep 10.DEM.PRX 10.bags 10.your there.is.no 1.person 1SM-FUT-10OM-take

Hamba u-yo-si-khelel(a) amanzi”. Kanti ba-li-nik-e i-emela

walk 2sSM-IT-1POM-draw.for 6.water kanti 2SM-5SOM-give-PRF 9.bucket

e-vuza-yo. La-hamb(a) izim, la-yo-kh(a) amanzi, zigqu, zigqu, kanti

9RC-leak-REL 5PST-walk 5.giant 5PST.SBJV-IT-draw 6.water zigqu zigqu kanti

ba-shiyeke be-vul(a) ezi ngxowa, ba-khuph(a)aba bantwana

2SM-remain 5PRT-open 10.DEM.PRX 10.bags 5PST-remove 2.DEM.PRX 2.children

ba-ba-tshixela kwe-nye indlu. Ba-fak(a)oononyevu, ba-fak(a) iinyoka bafak(a) 2PST-2OM-lock.into LOC-one 9.house 2PST-put 2a.reptiles 2PST-put 10.snake 2PST-put

amasele, kwe-zi ngxowa. Li-xakiw-(e) izim pha. Li-ba-so ${ }^{22}-k h a$

6.frog LOC-10.DEM.PRX 10.bags 5SM-be.confused-PRF 5.giant there 5PRT-2OM-PRT-draw

nge-emere, amanz(i)amanz(i) a-ya-vuz(a) "he-e-e-e!!!!" li-phind-e li-phind-e INSTR-9.bucket 6.water 6.water 6SM-DJT-leak he-e-e-e 5SM-return-PRF 5SM-return-PRF

li-kh(a) amanzi, iyho! Amanz(i)a-ya-vuza “h-o-o-o-o!!!” hayi la-ncama 5SM-fetch 6.water yho 6.water 6SM-DJT-leak h-o-o no 5PST-give.up

la-goduk(a) izim li-hamb-e li-ngxol(a) aph(a)e-ndlel-eni, "ba-ndi-nik-(e) 5PST-go.home 5.giant 5CT-walk-PRF 5CT-rant here LOC-9.road-LOC 2SM-1sOM-give-PRF iemer(e) e-vuza-yo mna, ba-ndi-nik-(e) iemer(e) e-vuza-yo mna”. 9.bucket 9RC-leak-REL me 2SM-1sOM-give-PRF 9.bucket 9RC-leak-REL me

\footnotetext{
${ }^{21}$ This is not heard but is required (Nozibele Nomdebevana, p.c.).

${ }^{22}$ Hypothesised to be the participial affix mentioned in footnote 20, unclear why this is $s o$ - in this case.
} 
Li-fik-il(e) e-mz-ini, la-fika la-yi-jula phaya

5SM-arrive-PRF LOC-3.homestead-LOC 5PST-arrive 5PST-9OM-throw.down there

le bhakethe ngoba li-ya-bon(a) into yo(ku)ba i-ya-vuza

9.DEM.PRX 9.bucket because 5SM-DJT-see 9.thing that 9SM-DJT-leak

La-thi "sapha-n(i) iingxowa zam ndi-goduk-e!" A-yi-kho le nto 5PST-say give.me-PL10.bags 10.my 1sSM-go.home-SBJV NEG-9NEG-be 9.DEM.PRX 9.thing

be-ni-ndi-thuma yona! Ba-zi-ni+ la-zi-nikwa izim iingxowa, CT-2pSM-1sOM-send 9.pro 2SM-10OM-give+ 5PST-10OM-give.PASS 5.giant 10.bags

la-goduka, li-vuya nga-phakathi li-zi-xelel(e) into(yoku)ba li-yo-xhel(a) 5PST-go.home 5PRT-be.happy LOC-inside 5PRT-REFL-tell-PRF that 5SM-IT-slaughter ezi nyamakaz-ana la-fik(a) e-ndl-ini, la-khwaza: "Nomahamle-e-e-e!!!" 10.DEM.PRX 10.game-DIM 5PST-arrive LOC-9.house-LOC 5PST-call Nomahamle

Li-no-mntwan(a) o-yi-ntombazana. “Ma-a-ma!” "Bas(a) umlil(o) u-be-mkhulu!!” Hayi ke 5SM-CONN-child REL-9COP-9.girl mama kindle 3.fire 3SM-CT-big no then

wa-bas(a) uNomahamle, wa-bas(a) uNomahamle, la-fik(a) izim la-val(a) 1PST-kindle uNomahamle 1PST-kindle uNomahamle 5PST-arrive 5.giant 5PST-open

emnyango. Umlil(o) u-ya-vutha, jonga. Li-zo-(ku)pheka abantwana. La-thi

3.doorway 3.fire 3SM-DJT-burn look 5SM-FUT-cook 2.children 5PST-say

a-ndi-fun-i ne-mbobo e-ncinane uk(u)ba ba-zo-phum(a) abantwana

NEG-1sSM-want-NEG CONN-9.hole 9AC-small so.that 2SM-FUT-come.out 2.children

kwe-zi ngxowa ba-balek-e. La-tshix(a) e-mnyango. Lavul(a) iingxowa LOC-10.DEM.PRX 10.bag 2PST-run-SBJV 5PST-lock LOC-3.doorway 5PST-open 10.bags

yalo ${ }^{23}$, la-vula zo-mbini. a-a-yhu!! Oononyevu iinyosi, iinyoka, pron 5PST-open 10AS-two ayhu 2a.reptile 10.bee 10.snake

zi-ya-tsiba-tsiba, zi-ya-li-thi li-ya-khal(a) izim, iyho-o-o!!! iyho-o-o-o!!! 10SM-DJT-jump-jump 10SM-DJT-5OM-say 5SM-DJT-cry 5.giant yho yho

$K u^{24}$-khon(a) umphand(a) o-bu-m-khulu ke phaya entla. Umphand(a) 17SM-be 3.barrel 3RC-14NCP-3AC-big then there LOC.inside 3.barrel

ubu-zaliswe nga-manzi. La-balek(a) izim la-yo-zi-fak(a) e-mphand-eni 3CT-fill.PASS INSTR-6.water 5PST-run 5.giant 5PST-IT-REFL-put LOC-3.barrel-LOC

nge-ntloko, a! zum! iyho bantwana bam la-li-nga-sa-khal-i, INSTR-9.head a zum yho 2.child 2.my 5PST-5CT-EMPH-PRT-cry-EMPH

\footnotetext{
${ }^{23}$ The narrator says yaso, but this is most probably a mistake, according to my consultants.

${ }^{24}$ Noun class 3 agreement $u$-khon(a) umphand(a) is expected for standard Xhosa (Thembani Onceya, p.c.).
} 
kodwa ke ngoku la-rhaxwa nga-manzi la-fa izim. Phaya e-khaya but then now 5PST-choke COP-6.water 5PST-die 5.giant there LOC-home

nga-se-mva, abantwana ba-goduswa ba-siwa e-khaya.

INSTR-LOC-back 2.children 2SM-bring.home.PASS 2SM-take.PASS LOC-home

Na-lo ke ibali lethu. Phelaphela nga-ntsomi.

CONN-5.this then 5.story 5.our finish finish INSTR-9.story

Translation ${ }^{25}$ :

(Narrator: Once upon a time... [You must all say chosi (to say chosi is to grab the attention)] Children: $\mathrm{Chosi}^{26}$ )

Narrator: ...there was a woman who had two daughters. One day, these daughters asked to visit their uncle. Their mother instructed them about how to get to their uncle: "When you reach the crossroad, you will see two roads diverging; one goes to the right and the other one goes to the left." The girls prepared themselves. Their mother cooked snacks for them and slaughtered a chicken so that, when they got hungry on their way, they could eat. They prepared themselves with joy because this would be their first time to visit their uncle. They woke up early in the morning; they prepared, washed themselves, took their small bags and put their clothes inside. One of them was older and the other one was younger. They left while their mother was saying goodbye to them: "Goodbye my children, travel safely." "Remember, especially you, Nontsokolo, take the left road. Don't take the right road, you will get lost." They both agreed: "Yes mama!"

They travelled in happiness. They were jumping up and down and tickling each other: "Yho! We are going to uncle!" "Wow, we are going to see uncle!" The sun set. When they arrived at those two diverging roads - one disappearing to the left and one disappearing to the right - they stopped. The young one said, "Nontsokolo, what way did mother instruct us to take, on which road should we walk?" Nontsokolo said: "Mother instructed us to take the one to the right." Yho, Vathiswa totally disagreed with that. She said, "No Nontsokolo, mother instructed us to take the road to the left, we should not take the one to the right." They argued until it became dusk.

Nontsokolo took the one to the right because she was the oldest. Vathiswa, the small one, had no alternative but to follow Nontsokolo. They walked the road to the right, the one they were told not to take because they would get lost. They walked, walked and walked until they got into the forest.

(Narrator is talking to the audience) "Tell me my children, when kids enter into the forest after sunset without knowing (the way), are they going to get to their uncle?" Yho, the trees were shaking because the animals of the forest were trying to sleep at that time. Birds were singing: tyululukuthu,tyululukuthu. Yho! Monkeys: tyo! tyo!, tyo! tyo!

\footnotetext{
${ }^{25}$ In this translation, the attempt has been made to stay as close as possible to the Xhosa text, with reasonable English.

${ }^{26}$ Further comments from the children in the recording are left out of the transcription/translation.
} 
Yho!!! Vathiswa was afraid as she was the youngest one. Nontsokolo said, "Come Vathiswa and let me hold you by your hand, because I can see that you are afraid." They walked, walked, walked and walked. Vathiswa said, "No, Nontsokolo, why is it like we don't get out of this forest, we have just been walking around, yho!" Nontsokolo said, "No, be patient daughter of my mother, Vathiswa, we are close to an exit." It happened that at night as they were walking, they saw lights glimmering in a distance. Vathiswa, the youngest, said, "It seems like there's a light over there, is it where uncle stays?" Nontsokolo said "Yes, we are almost there." They walked, walked and walked until they came out of the forest.

It happened that when they came close to the house with the light, they heard the growling of a giant. The giant was exhausted and sleeping close to the door and its bag was lying next to it because it was coming from hunting. Yhiyho-o-o!!! What is the giant saying? "Hee yhee phephephe!!!" Vathiswa was very scared: "Yhooo!!! Nontsokolo! What are we going to do, we will be eaten by the giant!" It happened that when she said that, the giant was startled, woke up and sat down, saying "Fakatha, fakatha, why is there a smell of a human here? Fakatha, fakatha, why is there a smell of a human here?" Yho-o! Nontsokolo, the older one, was also scared now, she said: "Yho! Mother said we should not take this route." Yho! The giant stood up, jumped and caught both of them. The giant put them into the two bags, Vathiswa in one bag and Nontsokolo in another. The giant opened holes in the bags so that they could breathe. It tied the bags and guarded them. The giant said, "I will eat you on a rainy day." Yho, they were scared inside the bags, they were really scared inside the bags.

The giant slept at night holding the bags; it did not want them to escape. Yho, in the morning the roosters crowed Kurukugu!!! Yho! In the morning, the giant woke up and went to fetch water where it was available. This was when the giant passed a house where a cow was being slaughtered. It was called, "Come this side $\operatorname{man}^{27}$, we will give you pieces of meat."

The giant passed the house carrying these bags, it walked, $g q u, g q u, g q u, g q u$. When it got there, it put the bags down. It was told "Take this here so that we can pour you something to drink." The giant drunk $h i-i h i-i h i-i$, and that is when they got suspicious that there might be people in those bags. They sent the giant to get them water. One of the men said: "I will watch your bags and no one will touch them. Go and fetch us water." But they gave him a leaking bucket.

The giant went to fetch water, zigqu, zigqu, and during this time they opened the bags, took out the children and locked them in another house. They put reptiles, snakes, and frogs in the bags. The giant was confused. Fetching water with a bucket that is leaking he-e-e-e!!! It tried to fetch water again and again but the water was leaking out.

The giant gave up and went back making loud noises on the way: "They gave me a bucket that leaks, they gave me a bucket that leaks." It arrived at the homestead and threw down the bucket because it realised that it was just leaking. The giant said "Give me my bags so that I can walk home! There's nothing you have sent me to fetch water for!" They gave the bags to the giant, it went home, the giant was happy, knowing that it was going to slaughter.

\footnotetext{
${ }^{27}$ The pronoun used to refer to the giant in the translation is "it". Xhosa does not distinguish between "he" and "she", and the gender of the giant is ambiguous in the story. The slaughtering men call the giant "man", but later in the story the daughter Nomahamle calls the giant "mama".
} 
When the giant got home, it shouted: "Nomahamle-e-e-e-e!!!" It had a child who was a girl. "Ma-a-ma!" "Make a very big fire!!" Nomahamle kindled a fire, Nomahamle kindled a fire, the giant arrived and closed the door. Look, the fire was burning. The giant was going to cook the children. It said, "I don't want any hole that these children can use to get out of these bags and run." The giant locked the door and opened both bags. A-a-yhu!! Nasty! The reptiles, bees, and snakes were jumping up and down, and the giant was crying: "Yho-o-o!!! Yho-o-o!!!" There was a big container inside this house. This big container was filled with water. The giant rushed to the big container to put its head inside, "Aaaah!" Zum! Yho my children, the giant was really crying, but it drowned inside the container and died. There in the backyard, the children were taken home.

Here is our story. The end.

\section{Reference}

Allwood, J. and R. Hendrikse. 2005. Guidelines for developing spoken language corpora. In J. Allwood et al. (eds.) Spoken African language corpora series. Pretoria, South Africa: UNISA, Dept of Linguistics. 